\title{
Virtual reality in the rehabilitation of the balance in the elderly.
}

\author{
Juliana Alencar de Oliveira(1), Thaís Feitosa Guaratto(1), Jéssica Maria Ribeiro Bacha(1), Roberta A. G. T. Evangelista(2), \\ Danilo Sales Bocalini(2), Júlia Maria D'Andrea Greve ${ }^{(3)}$, Angélica Castilho Alonso ${ }^{(2,3)}$
}

\begin{abstract}
Introduction: Aging is characterized by a series of changes and adaptations that occur in the body progressively and irreversibly over the years. One of the consequences of senescence is the deficit of maintaining balance, this fact is explained by the involvement of the visual, somatosensory and vestibular systems. Given this scenario, the use of tools that can minimize these declines is of paramount importance. In recent times a resource that has been investigated is virtual reality, this technique stands out for presenting cognitive, motor and cardiorespiratory demands beneficial to the elderly. Objective: The present study aimed to perform a narrative review on the influence of virtual reality on the rehabilitation of balance in healthy elderly. Methods: A bibliographic survey was carried out in Portuguese and English, in the electronic databases: Pubmed, Lilacs, Pedro, Scielo, Scopus and Cochrone. A temporal limiter was applied from 2010 to 2015. Results: We selected 84 articles, however only five fit the criteria of the research. Despite the different methodologies and sample used, all articles selected showed significant improvement in postural balance after virtual reality therapy. However, a lack of standardization of the research protocols can be observed, making it difficult to reach a precise conclusion regarding the real effects of this technique for the study population. Conclusion: Virtual reality therapy was shown to be effective for the rehabilitation of postural balance in healthy elderly individuals. However, such evidence needs to be further investigated in future studies.
\end{abstract}

Keywords: Aged; Balance Postural; Rehabilitation; Physical Therapy; Virtual Reality; Elderly.

\section{INTRODUCTION}

Aging consists of a natural and irreversible process, which occurs from birth to death. This is characterized by a series of changes and adaptations that occur in the body progressively and irreversibly over the years ${ }^{(1,2)}$.

One of the consequences of senescence is the deficit of maintaining balance, this fact is explained by the involvement of the visual, somatosensory and vestibular systems. These are responsible for maintaining the balance, by informing the central nervous system of the head and body movements as well as their positions in relation to space and interaction with the environment ${ }^{(3,4)}$. The received information is processed and a response is sent by the central nervous system to maintain postural balance by tweaking the anticipatory or compensatory ${ }^{(4,5)}$.

Aging has been a growing concern in public health. Due to the high costs caused mainly by the falls which are responsible for large numbers of hospitalizations, morbidities and mortality in elderly patients ${ }^{(6,7,8,9)}$. Approximately $30 \%$ of the elderly suffer at least one fall within a year. One of the main causes of these falls is the balance deficit ${ }^{(7,10)}$.
New modes of interventions for improving balance have been applied. According to Aylett and Luck ${ }^{(11)}$, the virtual reality (VR) consists of a technology characterized by an interface which integrates varying degrees of immersion, interaction and user involvement when using multisensory devices, from a three-dimensional environment created in real time by a computer. In this modality, the user interacts with the images displayed and may move and manipulate virtual objects, experiencing environment and the simulated task ${ }^{(9,12,15)}$. It is estimated that the VR began to be used as a rehabilitation tool in the transition between the twentieth to the twenty-first centuries ${ }^{(16-18)}$. It has being seen as an innovative and promising therapy in rehabilitation technology, since its benefits may transcend the purely physiological and clinical aspects of the rehabilitation ${ }^{(4,17)}$. As the main objective for rehabilitation with the use of VR may be mentioned an increase in the functional capacity and better inclusion of the individual in the participations of its tasks of daily life due to the improvement of the motor, cognitive and sensorial function ${ }^{(15)}$.

\footnotetext{
Corresponding Author: Angélica Castilho Alonso. Universidade São Judas Tadeu, Rua Dr. Taquari, 546, São Paulo, SP, Brazil. E-mail: angelicacastilho@msn.com

São Judas Tadeu University (USJT), SP-Brazil.

${ }^{3}$ Hospital das Clinicas, Faculty of Medicine, São Paulo University (USP), SP-Brazil.

Full list of author information is available at the end of the article.

Funding: The authors declare no financial support.
}

Submission date 13 April 2017; Acceptance date 02 August 2017; Publication date 19 September 2017 
However, it is possible to find some obstacles in relation to the use of this technology, such as the technological devices cost, lack of consensus in the literature, inconsistency of results and the methodology. Moreover, it is a type of technological rehabilitation which is not yet accessible to most the population.

It is necessary for health professionals to recognize the influence, benefits, advantages and disadvantages of balance rehabilitation in the elderly with the use of VR to be able to use it in the best way in clinical practice.

Thus, the present study aimed to make a narrative review on the influence of virtual reality in rehabilitation of balance in the elderlies.

\section{METHODS}

The study was developed in the Laboratory of the Study of the Movement of the Institute of Orthopedics and Traumatology of the Faculty of Medicine of the University of São Paulo (FMUSP).

Research strategy: The narrative review was performed in the following electronic databases: PubMed, Lilacs, Pedro, SciELO, Scopus and Cochrane. The research aimed to find published articles on the influence of virtual reality on the balance of healthy elderly, using the following scientific descriptors: Postural balance, Elderly, Rehabilitation, Physiotherapy, Virtual Reality Exposure Therapy, in Portuguese and English. It was performed in the period of 2010 to 2015. Thus, the content of the databases was selected according to the years of publication and keywords.
Review process: Through the descriptors, 84 articles were identified. After reading the titles and abstracts, 47 articles were excluded, four of which were duplicates. After full reading, five items remained which have been eligible for this study, as illustrated by the flowchart in Figure 1.

\section{RESULTS}

84 articles were found in the bibliographic survey. After reading the titles, 36 were excluded because they considered static or dynamic balance deficits in non-elderly and/or unhealthy individuals affected by: Stroke, Parkinson's, Multiple sclerosis, Diabetes, Vertigo and Traumatic brain injuries, as well as bibliographic review articles. In some articles, it was not possible to detect the exclusion criteria by title, thus 10 articles were excluded only after reading the abstract. 4 duplicate studies were discarded, 9 articles were selected for reading in full, however only 5 are embedded in the objective of this bibliographic review according to Table 1 .

\section{DISCUSSION}

Despite the employed methodological and sample differences, all selected articles showed a significant improvement in postural balance after virtual reality therapy. It is worth mentioning the study of Singh et al. ${ }^{(22)}$ which analyze virtual reality effect compared to conventional therapy to improve balance, in which it was used a sample with women aged equal to or above 56 , however the average age of was $61.12 \pm 3.72$ in the experimental group and $64.00 \pm 5.88$ for the control group. Therefore, this study was considered adequate for this review.

Keyw ord: Postural balance, Aged, Rehabilitation, Physiotherapy, Therapy of exposure to virtual reality

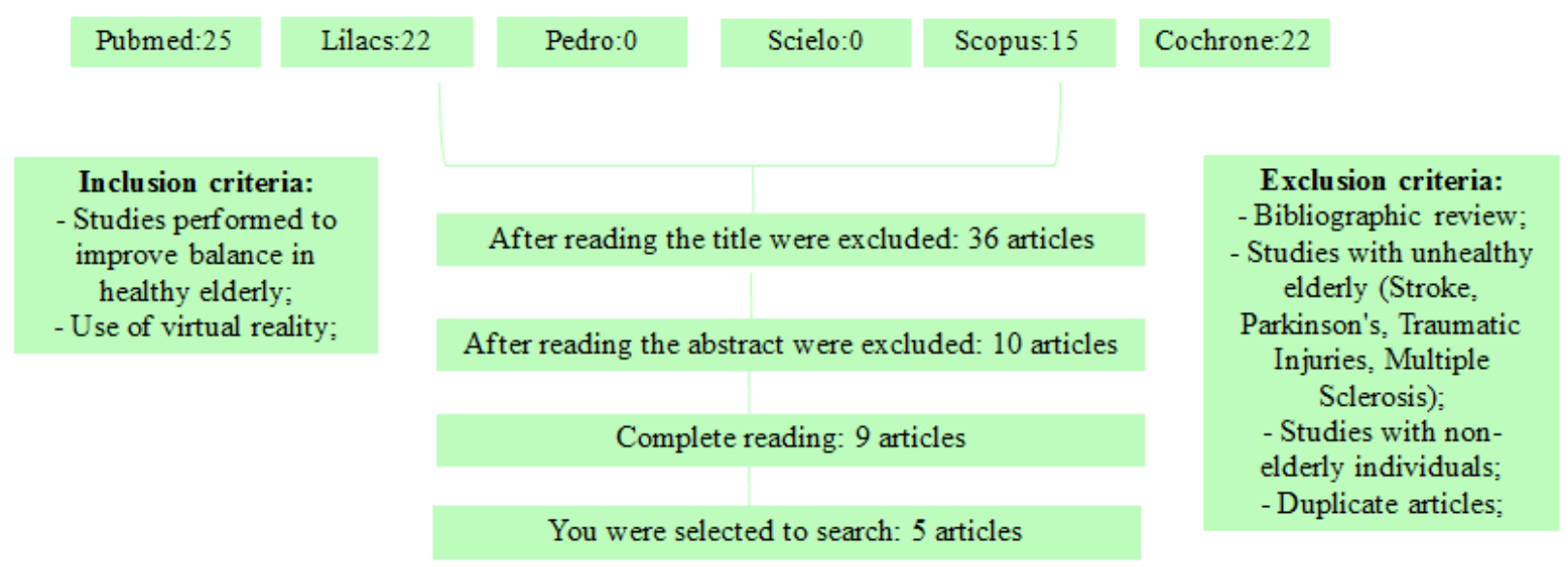

Figure 1: Research flowchart related to Virtual Reality in the balance of the elderly 
Table 1: Selected articles for the Virtual Reality review of the elderly balance

\begin{tabular}{|c|c|c|c|c|}
\hline Articles & Causes & Methods & Results & Conclusion \\
\hline \multirow{2}{*}{$\begin{array}{c}\text { Effects of balance training } \\
\text { a virtual-reality system in } \\
\text { older fallers. (Duque et al. } \\
\text { 2013) }\end{array}$} & \multirow{2}{*}{$\begin{array}{l}58 \text { individuals of both } \\
\text { genders }\end{array}$} & $\begin{array}{l}\text { Experimental group: Training } \\
\text { with virtual reality (BRU) and } \\
\text { fall prevention booklet }\end{array}$ & \multirow{2}{*}{$\begin{array}{l}\text { In the experimental group, a } \\
\text { significant improvement in } \\
\text { balance parameters after } 6 \\
\text { weeks of virtual reality (BRU), } \\
\text { greater stability limit and } \\
\text { reduction of fear and falls was } \\
\text { identified. }\end{array}$} & \multirow{2}{*}{$\begin{array}{l}\text { BRU is an effective method } \\
\text { to provide balance training } \\
\text { for fall prevention in the } \\
\text { elderly. It should be employed } \\
\text { to supplement program } \\
\text { interventions for improved } \\
\text { balance. }\end{array}$} \\
\hline & & $\begin{array}{c}\text { Control group: Conventional } \\
\text { treatment - Fall Prevention } \\
\text { booklet }\end{array}$ & & \\
\hline \multirow{2}{*}{$\begin{array}{l}\text { Participating in a virtual } \\
\text { reality balance exercise } \\
\text { program can reduce } \\
\text { risk and fear of falls } \\
\text { (Singh et al. 2012) }\end{array}$} & \multirow{2}{*}{$\begin{array}{l}36 \text { postmenopausal } \\
\text { women }\end{array}$} & $\begin{array}{l}\text { Experimental group: Exercises } \\
\text { using virtual reality games for } \\
\text { balance }\end{array}$ & \multirow{2}{*}{$\begin{array}{l}\text { Both groups had improved } \\
\text { balance and confidence as well } \\
\text { as reduced risk of falls. There } \\
\text { was no statistically significant } \\
\text { difference between the two } \\
\text { therapies. }\end{array}$} & \multirow{2}{*}{$\begin{array}{l}\text { The virtual reality may } \\
\text { be introduced during } \\
\text { the rehabilitation of } \\
\text { postmenopausal women to } \\
\text { improve their confidence, } \\
\text { balance and reduce the risk of } \\
\text { falls. It may be performed at } \\
\text { home as a leisure activity. }\end{array}$} \\
\hline & & $\begin{array}{l}\text { Control group: Conventional } \\
\text { exercises for balance }\end{array}$ & & \\
\hline \multirow{2}{*}{$\begin{array}{l}\text { The effect of virtual } \\
\text { reality gaming on dynamic } \\
\text { balance in older adults } \\
\text { (Rendon et al.2012) }\end{array}$} & \multirow{2}{*}{$\begin{array}{c}40 \text { adults (60 and } 95 \\
\text { years old) }\end{array}$} & $\begin{array}{c}\text { Experimental group: To use } \\
\text { the virtual reality with WBB } \\
\text { game with the Nintendo Wii fit } \\
\text { software package }\end{array}$ & \multirow{2}{*}{$\begin{array}{l}\text { There was significant } \\
\text { improvement for the } \\
\text { experimental group in relation } \\
\text { to movement in functional } \\
\text { activities. }\end{array}$} & \multirow{2}{*}{$\begin{array}{l}\text { The results suggest that wii fit } \\
\text { virtual reality gaming systems } \\
\text { improve balance, postural } \\
\text { stability, and confidence with } \\
\text { functional activities. There was } \\
\text { no significant change in relation } \\
\text { to depression scales. }\end{array}$} \\
\hline & & $\begin{array}{l}\text { Group control: Received only } \\
\text { pretest measurements and } \\
\text { evaluations }\end{array}$ & & \\
\hline
\end{tabular}

Experimental Group: Exercises using the Nintendo Wii balance board with several games.

Participants were progressing within each step of the game and within their own pace.

Effects of balancefocused interactive games compared to therapeutic balance classes for older woman (Singh at al. 2013)
46 women aged $56 \quad$ Group control: Balance tasks years and over

like: unipodal, swing free leg, move objects forward, backward and sideways and walk sideways and backwards. Progression with increasing speed and complexity of each task (closed eyes, unstable support).
Significant improvement was observed in the experimental group which participated in therapy for balance with virtual reality.
Virtual reality improves agility, balance and functional mobility, the VR technique may be used as rehabilitation protocols and strategies to maintain elderly mobility and fall prevention.
Does a Wii-based exercise program enhance balance control of independently functioning older adults? A systematic review (Laufer et al. 2014)
Systematic review CINAHL, Pedro, EMBASE, SPORTDiscus, Google Scholar and FullSearch
Initial screening of 351 papers, 39 were relevant by title and abstract, after reading in full there remained 7 randomized controlled trials.
The review found that engaging community elders in a Wiibased exercise program is doable and can increase their ability to balance.
Experimental Group: Participants were briefed on how the motion sensors of the virtual reality game worked in the first session. The

Unsupervised virtual reality-based exercise program improves hip muscle strength and balance control in older adults: A pilot study (Kim et al. 2013)
36 elderly people of both genders movements performed were: hip and knee flexion in one leg and lateral rhythmic oscillations in the other leg.

Group control: it performed the movement before and after the test, however did not engage in an exercise program and were instructed to continue with a normal routine for a period of
There was statistically

The virtual reality program showed improvement in quadriceps strength and improved dynamic balance control in older adults. strength of extensors, flexors and hip adductors, improved balance in open eyes, closed feet, and moving.
Therefore, VR is a useful too to improve the decrease in the physical function of the elderly.

8 weeks. 
The virtual reality has been widely used in the process of rehabilitation of individuals after stroke, cerebral palsy and brain injuries. However, the application of such technology for the prevention of falls has been limited due to the scarcity of studies which used virtual reality to train the balance and prevent falls in the elderly ${ }^{(19)}$. However, some studies showed the importance of inclusion of this modality in the treatment of balance disorders in elderly $(13,19,20)$.

The present study aimed to verify in the literature the relation of the benefits of virtual reality in the postural balance of healthy elderly people. Although the selected studies vary in gender, sample size and age (56 to 95 years), all were unanimous in presenting significant improvement of postural balance after therapy with virtual reality.

All the studies had a control group in their methodology. The studies of Singh et al. ${ }^{(21,22)}$ applied conventional exercises for balance, and Duke et al. ${ }^{(19)}$ in addition to conventional therapy, they also delivered a booklet on preventing falls. The control group of the Rendon ${ }^{(20)}$ and Kim ${ }^{(20)}$ studies did not participate in any rehabilitation protocol only performed the measurements and evaluation pre- and post-test reviews and they were advised to continue the daily routine.

Rendon et al. ${ }^{(23)}$ performed in their assessments the application of Balance Confidence Scale and Geriatric Depression Scale at the beginning and the end of balance training. Singh et al. ${ }^{(21)}$ also used to Balance Confidence Scale and the evaluation of fall risk which was analyzed by a computer program called FallScreen ${ }^{\odot}$ pre- and post-rehabilitation. However, the study of Singh et al., (22) applied in their pre- and post-training participants the Time up and go test, ten-step test to assess agility and the intelligent balance board connected to a computer which punctuates mid-lateral and anterior-posterior oscillations. Duke et al., ${ }^{(19)}$ used as an evaluation method the posturograph the Balance Rehabilitation Unit (BRU) which consists of a recently validated method which evaluates and trains the balance by varying somatosensory, visual and vestibular conditions. The participants underwent evaluation at the beginning, at the sixth week and at the 9th month. Different all other studies Kim et al. ${ }^{(20)}$ used a Xbox to analyze the movements performed in which were captured by the pre- and post-therapy sensor.

Regarding the treatment time, the studies show an agreement in six-week holding two sessions per week ${ }^{(19,21,22)}$. Except Rendon et al. ${ }^{(23)}$ which performed 18 sessions divided into three times a week and Kim et al., ${ }^{(20)}$ which distributed the sessions in the three times a week during 8 weeks.

Niintendo Wii is a device which uses the advanced technology and has been used in the sensorimotor training ${ }^{(4)}$. The studies of Singh et al, . ${ }^{(22)}$ Rendon et al. ${ }^{(23)}$ and Singh et al. ${ }^{(22)}$ used this tool for the experimental group. The participants of the Singh et al. study ${ }^{(21)}$ were subjected to various games requiring anteroposterior and mediolateral movement, however in the Rendon et al. ${ }^{(23)}$ and Singh et al. ${ }^{(22)}$, the subjects were submitted to the Nintendo Wii Fit Software using the platform.

The participants in the study Duqye et al. study ${ }^{(19)}$ were submitted to BRU posturograph which engaged in visual-vestibular rehabilitation, postural training and virtual reality exercises for improving balance. Three different games were used with increasing levels of complexity. The levels were progressed when the individual reported to be ease and correct posture. When completing the weeks of treatment, the participants were submitted to a new report in the posturograph, this was compared to the initial report.

Kim et al. ${ }^{(20)}$ in its experimental group, it was applied some yoga and Tai Chi movements captured by the sensors Xbox 360 . The subjects could follow the avatar projected on the screen or move freely, the training may be revised at the end of the activity. A virtual trainer provided visual and verbal feedback on the movements performed ensuring the exercise was correctly performed. The software had a score system of performance, and it was used to encourage the participant to perform the exercises as correct as possible.

Despite the differences in study types, sample size and gender, all studies were unanimous in stating that virtual reality is effective in improving postural balance in healthy elderly people.

\section{FINAL CONSIDERATIONS}

The virtual reality showed to be effective in being addressed in a postural balance rehabilitation program in healthy elderly. However, such evidence must be investigated using larger samples and similar methodologies.

\section{AUTHORS' CONTRIBUTIONS}

JAO, TFG, JMRB, RAGTE, have collaborated at the design, construction and corrections of the article; DSB performed the article correction at different phases; JMDAG corrected the final version of the article; ACA head of the study.

\section{CONFLICT OF INTEREST}

The authors declare no conflict of interest.

\section{AUTHOR DETAILS}

${ }^{1}$ Faculty of Medicine, University of São Paulo (USP), SP-Brazil.

\section{REFERENCES}

1. Zago AS. Exercício físico e o processo saúde-doença no envelhecimento. Rev bras geriatr gerontol 2010;13(1):153-158.

2. Oliveira AC, Oliveira NMD, Arantes PMM, Alencar MA. Quality of life in elderly people who practice physical activity - a systematic review. Rev bras geriatr gerontol 2010;13(2):301-312.

3. Gazzola JM, Perracini MR, Ganança MM, Ganança FF. Fatores associados ao equilíbrio funcional em idosos com disfunção vestibular crônica. Rev bras otorrinolaringol 2006;72(5):683-90.

4. Braga MM, Nunes GS, Schütz GR, Menezes FS. Treinamento sensóriomotor com nintendo wii $^{\circledR}$ e disco proprioceptivo: efeitos sobre o equilíbrio de mulheres jovens saudáveis. Rev bras ci e mov 2012; 20(3):37-45.

5. Huang $\mathrm{MH}$, Brown $\mathrm{SH}$. Age differences in the control of postural stability during reaching tasks. Gait posture 2013;38(4):837-42. 
6. Gomes GAO, Cintra FA, Batista FS, Neri AL, Guariento ME, Souza MLR et al. Perfil de idosos em acompanhamento ambulatorial e preditores de quedas. São Paulo med. J 2013; 131(1): 13-18.

7. Albino ILR, Freitas CDLR, Teixeiro AR, Gonçalves AK, Santos AMPV, Bós AJG. influência do treinamento de força muscular e de flexibilidade articular sobre o equilíbrio corporal em idosas. Rev bras geriatr. gerontol 2012;15(1):17-25.

8. Meneses SRF, Burke TN, Marques AP. Equilíbrio, controle postural e força muscular em idosas osteoporóticas com e sem quedas. fisioter pesqui 2012;19(1):26-31.

9. Pietrzak E, Cotea C, Pullman S. Using commercial video games for falls prevention in older adults: the way for the future? Journal of geriatric physical therapy 2014;37(4):166-177.

10. Santos SSC, Silva ME, Pinho LB, Gautério DP, Pelzer MT, Silveira RS. Risk of falls in the elderly: an integrative review based on the north american nursing diagnosis association. Rev esc enferm usp 2012;46(5):1227-1236.

11. Aylett R, Luck M. Applying artificial intelligence to virtual reality: intelligent virtual environments. Applied artificial intelligence 2000; 14(1):3-32.

12. Booth V, Masud T, Connell L, Bath-hextall F. The effectiveness of virtual reality interventions in improving balance in adults with impaired balance compared with standard or no treatment: a systematic review and metaanalysis. Clinical rehabilitation 2014; 28(5):419-431.

13. Laufer Y, Dar G, Kodesh E. Does a wii-based exercise program enhance balance control of independently functioning older adults? a systematic review. Clin interv aging. 2014; 23(9):1803-13.

14. Rahman SAR. Efficacy of virtual reality-based therapy on balance in children with down syndrome. World applied. Sciences journal. 2010;10 (3):254-261.
15. Loureiro APC, Ribas CG, Zotz TGG, Chen R, Ribas F. Feasibility of virtual therapy in rehabilitation of parkinson's disease patients: pilot study. Fisioter mov 2012;25(3):659-66

16. Jack D, Boian R, Merians AS, Tremaine M, Burdea GC, Adamovich SV, Recce $\mathrm{M}$, Poizner $\mathrm{H}$. Virtual reality-enhanced stroke rehabilitation. ieee trans neural syst rehabil eng 2001;9(3):308-18.

17. Junior RSM, Carvalho RJP, Silva EB, Bastos FG. Efeito da reabilitação virtual em diferentes tipos de tratamento virtual. Revista brasileira de ciências da saúde 2011; 9(29).

18. Junior RSM, Silva EB. Effectiveness of the virtual rehabilitation on body balance and motor abilities of individuals with neuromotor impairment: A systematic review. Rev bras ativ fis e saúde 2012;17(3):224-230.

19. Duque G, Boersma D, Loza-Diaz G, Hassan S, Suarez H, Geisinger D, Suriyaarachchi $P$, Sharma A, Demontiero O. Effects of balance training using a virtual-reality system in older fallers. Clin interv aging 2013;8: 257-63.

20. Kim J, Son J, Ko N, Yoon B. Unsupervised virtual reality-based exercise program improves hip muscle strength and balance control in older adults: a pilot study. Archives of physical medicine and rehabilitation 2013(94):937-943.

21. Singh DKA, Rajaratnam BS, Palaniswamy V, Pearson $H$, Raman VP, Bong PS. Participating in a virtual reality balance exercise program can reduce risk and fear of falls. Maturitas 2012(73):239-243.

22. Singh DKA; Rajaratnam BS, Palaniswamy V, Raman VP, Bong PS, Pearson $\mathrm{H}$. Effects of balance-focused interactive games compared to therapeutic balance classes for older women. Climacteric 2013(16):141-146.

23. Rendon AA; Lohman EB, Thorpe D, Johnson EG, Medina E, Bradley B. the effect of virtual reality gaming on dynamic balance in older adults. Age and ageing 2012(41):549-552 